EESTI NSV TEADUSTE AKADEEMIA TOIMETISED. 20. KOIDE

KEEMIA * GEOLOOGIA, 1971, NR. 2

ИЗВЕСТИЯ АКАДЕМИИ НАУК ЭСТОНСКОИ ССР. ТОМ 20

Химия * ГЕОЛОГия. 1971, № 2

удК 543.544 .45

AHНЕ ОРАВ, О. ЭИЗЕН

\title{
ОПРЕДЕЛЕНИЕ НОРМАЛЬНЫХ ОЛЕФИНОВ В ДИСТИЛЛЯТАХ КОКСОВАНИЯ СЛАНЦЕВОЙ СМОЛЫ ПРИ ПОМОЩИ КАПИЛЛЯРНОИ ГАЗОВОЙ ХРОМАТОГРАФИИ
}

\begin{abstract}
Капиллярная газовая хроматография находит все большее применение для анализя сложных смесей углеводородов. В качестве неподвижной фазы обычно применлется неполярная жидкая фаза - сквалан. Колонки длиной до 200 м со скваланом нгпользуются для разделения смесей углеводородов, содержащих около ста компонентов.

Много работ посвящено исследованию нефтепродуктов, содержащих предельные углеводороды и ароматические соединения, на капиллярных колонках $\left[{ }^{1-9}\right]$. Реже встречаются в литературе данные о разделении олефинов при помощи капиллярной газовой хроматографии $\left[{ }^{10-17}\right]$.

Целью настоящей работы было определение состава олефиновых фракций дистиллята коксования сланцевой смолы. В качестве жидкой фазы капиллярной колонки яспользовался полярный полиэтиленгликоль 4000 , который, как показали предварительные опыты, четко разделял цис- и транс-изомеры олефинов до $\mathrm{C}_{11}$.
\end{abstract}

\section{Әкспериментальная часть}

Аппаратура. Для анализа применялся хроматограф «Хром-2» с пламенно-ионизационным детектором. Исследование проводилось на капиллярных колонках из нержавеющей стали длиной 40 и 80 м, внутренним диаметром 0,25 мл. В качестве неподвижной фазы использовался полиэтиленгликоль 4000, который был нанесен на внутренние стенки капилляра в виде $10 \%$-ного раствора в хлороформе [18]. Медная капнллярная колонка со скваланом имела длину $80 \mu$ и внутренний диаметр 0,25 мм. Газом-носителем служил азот.

Характеристика анализируемой смолы. В качестве исходного сырья для исследования служили дистилляты коксования сланцевой смолы, полученные при двух режимах коксования. При одном режиме установка работала с дефлегматором $(K)$, при другом - без дефлегматора $(R)$ (табл. 1).

Разгонка дистиллятов на узкие фракции осуществлялась на автоматической вакуумной дистилляционной колонке. Результаты ректификации приведены в табл. 2.

Фракции подвергались хроматографическому разделению на силикагеле с выделением отдельных групповых компонентов. Для адсорбционно-жидкостной хроматографии адсорбентом служил силикагель КСM (0,25-0,16 мм), весовое соотношение силикагеля и смолы $15: 1$, в качестве вытеснителя использовался этиловый эфир. 
Для тонкослойной хроматографии адсорбентом служил силикагель ШСМ $(0,16-0,05$ мм, размеры пла. стинки $24 \times 24$ см, толщина слоя 2 мм), а элюентом -петролейный эфир.

Мертвый объем колонки был определен при помощи времен удерживания трех следующих друг за другом H-парафинов $\left[{ }^{18}\right]$.

\section{Обсуждение результатов}

В табл. 4 приведены индексы Ковача, полученные на капиллярной колонке с полиэтиленгликолем 4000, для следующих углеводородов: для $\mu$-олефинов $\mathrm{C}_{5}-\mathrm{C}_{11}$, ароматических углеводородов $\mathrm{C}_{6}-\mathrm{C}_{11}$, циклопентенов, цикланов $\mathrm{C}_{5}-\mathrm{C}_{9}$. Эффективность капиллярной колонки с полиэтиленгликолем 4000 по н-нонану при $70^{\circ}$ равнялась 138200 ТТ. Колонка четко разделяла пространственные изомеры и изомеры связи. Пики 1-изомера и транс-3-изомера (для октенов и ноненов) в случае всех геометрических изомеров совпадали.
Таблица 1

Характеристика дистиллятов коксования сланцевой смолы

\begin{tabular}{|c|c|c|}
\hline Показатели & $\begin{array}{c}\text { Дистиллят } \\
K\end{array}$ & $\begin{array}{c}\text { Дистиллят } \\
R\end{array}$ \\
\hline $\begin{array}{l}\text { Удельный вес } d_{4}^{20} \\
\text { Показатель преломления } \\
n_{D}^{20} \\
\text { Фракционный состав, } \\
\text { вес. } \% \\
\text { до } 150^{\circ} \mathrm{C} \\
\Rightarrow 200^{\circ} \\
\Rightarrow 250^{\circ} \\
\Rightarrow 300^{\circ} \\
, 350^{\circ} \\
\\
\text { Результаты p }\end{array}$ & $\begin{array}{l}0,930 \\
1,5165 \\
18,0 \\
23,5 \\
29,0 \\
41,0 \\
60,5\end{array}$ & $\begin{array}{l}1,5452 \\
10,0 \\
15,0 \\
19,5 \\
29,0 \\
40,0 \\
\text { Таблица } 2\end{array}$ \\
\hline Показатели & $\begin{array}{c}\text { Дистиллят } \\
K\end{array}$ & $\begin{array}{c}\text { Дистиллят } \\
R\end{array}$ \\
\hline $\begin{array}{l}\text { Ректификационная часть, } \\
{ }^{\circ} \mathrm{C} \\
\text { Выход от исходной сме- } \\
\text { си, \% } \\
\text { Количество фракций } \\
\text { Пределы кипения, }{ }^{\circ} \mathrm{C} \\
\text { первой фракции } \\
\text { второй фракщии }\end{array}$ & $\begin{array}{c}96-437 \\
84,8 \\
30 \\
96-153 \\
153-205\end{array}$ & $\begin{array}{c}106-472 \\
57,3 \\
23 \\
106-159 \\
159-248\end{array}$ \\
\hline
\end{tabular}

\section{таб.ицца 3}

Условия хроматографического анализа

\begin{tabular}{|c|c|c|}
\hline \multirow[b]{2}{*}{ Показатели } & \multicolumn{2}{|c|}{ Жидкие фазы } \\
\hline & $\begin{array}{l}\text { Полиэтилен- } \\
\text { гликоль } 4000\end{array}$ & Сквалан \\
\hline Температура колонки, ${ }^{\circ} \mathrm{C}$ & $60-90$ & 80 \\
\hline Температура испарителя, ${ }^{\circ} \mathrm{C}$ & 200 & 200 \\
\hline Расход водорода, мл/минн & 35 & 40 \\
\hline Расход воздуха, мл/мин & 600 & 600 \\
\hline $\begin{array}{l}\text { Входное давление газа-носителя, } \\
\kappa 2 / c M^{2}\end{array}$ & 1,7 & 1,4 \\
\hline $\begin{array}{l}\text { Линейная скорость газа-носителя, } \\
\text { м/мин }\end{array}$ & 3 & 3,9 \\
\hline Выходное давление, ка/см ${ }^{2}$ & 1,0 & 1,0 \\
\hline Количество пробы, мкл & 2 & 1 \\
\hline
\end{tabular}

Кроме того, чтобы разделить 1-изомеры и транс-3-изомеры, были прсведены анализы олефиновых фракций также на капиллярной колонке со скваланом. На рис. 1 и 2 изображены хроматограммы олефиновой 
Индексы Ковача для углеводородов на капиллярной колонке с полиэтиленгликолем 4000

\begin{tabular}{c|c|c|c|c|c}
\hline $\begin{array}{c}\text { Номер } \\
\text { пика }\end{array}$ & $\begin{array}{c}\text { Название } \\
\text { вещества }\end{array}$ & \multicolumn{4}{|c}{ Температура колонки, ${ }^{\circ} \mathrm{C}$} \\
\hline 1 & 2 & 50 & 60 & 70 & 80 \\
\hline
\end{tabular}

$1 \quad$-Пентан

2 Пентен-1

3 -Гексан

4 Этиловый эфир

5 Циклопентан

6 Гексен-1

7 транс-Гексен-3

8 цис-Гексен-3

9 транс-Гексен-2

10 цис-Гексен-2

11 Метилциклопентан

$12 \mu$-Гептан

13 3-Метилциклопентен-1

14 Циклогексан

15 Гептен-1

16 транс-Гептен-3

17 цис-Гептен-3

18 транс-Гептен-2.

19 2-Метилциклопентен-1

20 цис-Гептен-2

21 Метилциклогексан

22 н-Октан

23 Циклогексен

24 1,4-Диметилциклогексан-транс

25 3-Этилциклопентен-1

26 транс-Октен-4

27 транс-Октен-3

28 Октен-1

29 циис-Октен-4

30 цис-Октен-3

31 3-Метилциклогексен-1

32 транс-Октен-2

33 1,4-Диметилциклогексан-цис

34 4-Метилциклогексен-1

35 2-Этилциклопентен-1

36 цис-Октен-2

37 Этилциклогексан

38 н-Нонан

39 1-Метилциклогексен-1

40 транс-Нонен-4

41 транс-Нонен-3

42 Нонен-1

43 цис-Нонен-4

44 цис-Нонен-3

45 Бензол

46 транс-НонеІг-2

47 цис-Нонен-2

48 3-Этилциклогексен-1

49 4-Этилциклогексен-1

50 Изопропилциклогексан

51 н-Декан

52 транс-Децен-4

53 транс-Децен-5

54 транс-Децен-3

55 цис-Децен-5

56 цис-Децен-4

57 Децен-1

58 цис-Децен-3

59 Толуол
500,0

546,4

600,0

634,3

648,5

656,4

660,1

663,4

679,8

700,0

688,8

718,7

742,0

747,7

747,7

756,2

763,8

778,9

776,2

789,3

824,3

828,3

832,4

839,0

847,2

847,2

852,7

854,0

863,3

867,0

866,6

876.4

900,0

907,3

864,0

877,5

900,0

939,2

945,8

947,7

948,5

952,2

963,2

976,7

976,8

981,1

987,0

1000,0

1037,3

1038,7

1043,9

1041,9

1044,2

1048,5

1049,5

1072.5 


\begin{tabular}{|c|c|c|c|c|c|}
\hline 1 & 2 & 3 & 4 & 5 & 6 \\
\hline $\begin{array}{l}60 \\
61\end{array}$ & $\begin{array}{l}\text { транс-Децен-2 } \\
\text { иис-Децен-2 }\end{array}$ & & & $\begin{array}{l}1062.0 \\
1073.7\end{array}$ & \\
\hline 62 & н-Ундекан & & & & 1100,0 \\
\hline 63 & транс-Ундецен-4 & & & & 1137,7 \\
\hline 64 & транс-Ундецен-5 & & & & 1137,7 \\
\hline 65 & транс-Ундецен-3 & & & & 1145.5 \\
\hline 66 & цис-Ундецен-5 & & & & 1142,1 \\
\hline 67 & цис-Ундецен-4 & & & & 1145,6 \\
\hline 68 & Этилбензол & & & & 1156,4 \\
\hline 69 & Ундецен-1 & & & & 1148.4 \\
\hline 70 & пара-Ксилол & & & & 1164,3 \\
\hline 71 & транс-Ундецен-2 & & & & 1161,1 \\
\hline 72 & цис-УНдецен-2 & & & 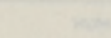 & 1176,4 \\
\hline 73 & мета-Ксилол & & & & 1170,3 \\
\hline 74 & Изопропилбензол & & & & 1198,5 \\
\hline 75 & орто-Ксилол & & & & 1213,2 \\
\hline $\begin{array}{l}76 \\
77\end{array}$ & $\begin{array}{l}\text { цис-Ундецен-3 } \\
\text { н-Додекан }\end{array}$ & & & & $\begin{array}{l}1151,7 \\
1200,0\end{array}$ \\
\hline
\end{tabular}

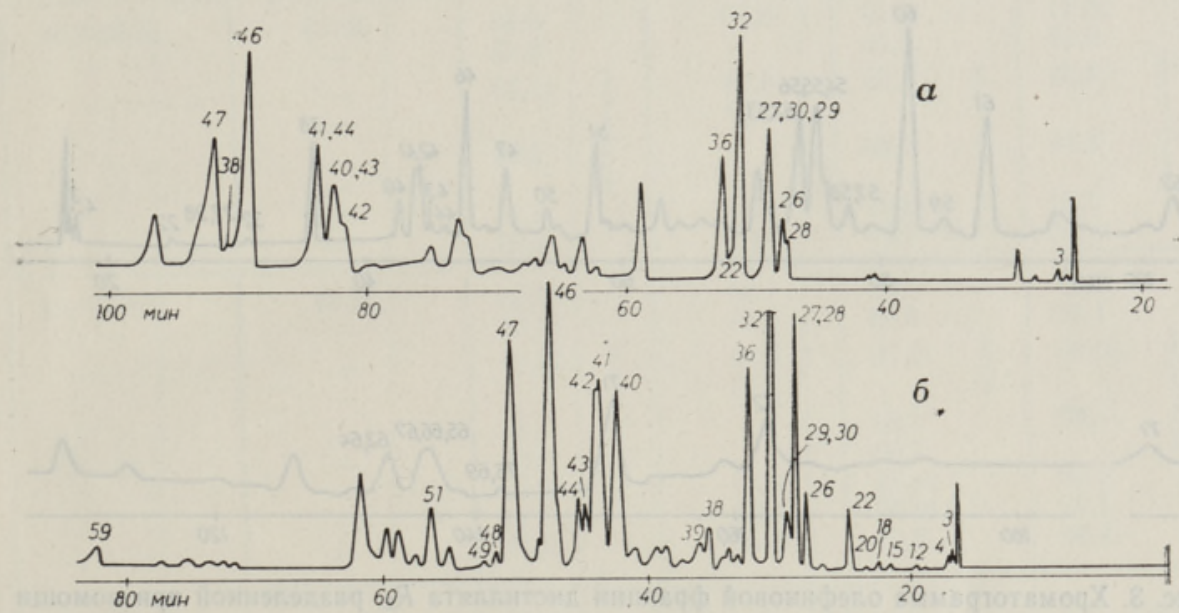

Рис. 1. Хроматограммы олефиновой фракции дистиллята $R_{1}$, разделенной при помощи адсорбционно-жидкостной хроматографии: $a-$ колонка со скваланом длиной $80 \mathrm{~m}$; температура колонки $79^{\circ} \mathrm{C}$; входное давление $1,49 \mathrm{\kappa z} / \mathrm{cm}^{2}$; б колонка с полиэтиленгликолем 4000 длиной $40 \mathrm{~m}$; температура колонки $62^{*}$;

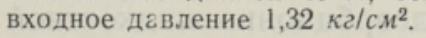

фракции $R_{1}$ на сквалане и полиэтиленгликоле 4000. Углеводороды, соответствующие пикам на хроматограмме, идентифицированы при помощи индексов Ковача.

Данные о составах олефиновых фракций дистиллятов $K_{1}$ и $R_{1}$, разделенных при помощи адсорбционно-жидкостной и тонкослойной хроматографий, приведены в табл. 5. Результаты показывают, что составы фракций $R_{1}$, определенные разными методамн, не совпадают. Во всех фракциях, полученных при помощи адсорбционно-жидкостной хроматографиі (кроме фракций $K_{1}$ ), сумма содержания цис-2- и транс-2-изомеров составляла до $40 \%$ от всех олефннов, а количество 1-олефинов толькэ $20 \%$ (табл. 5 и 6). Такие же результаты получены при анализе на капиллярной колонке со скваланом.

Состав фракций, разделенных в тонком слое, показал, что основными компонентами во фракциях являются 1-олефины. Это различие в содер- 


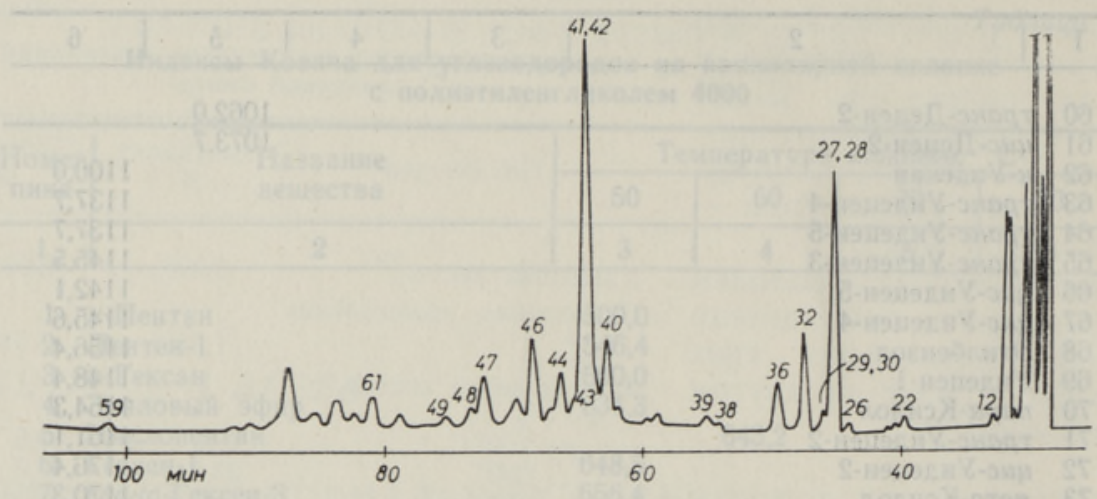

Рис.' 2. Хроматограмма олефиновой фракции дистиллята $R_{1}$, разделенной в тонком слое.

Капиллярная колонка с полиэтиленгликолем 4000 длиной 80 м; температура колонки $66^{\circ} \mathrm{C}$; входное давление 1,68 кг/с ${ }^{2}$.

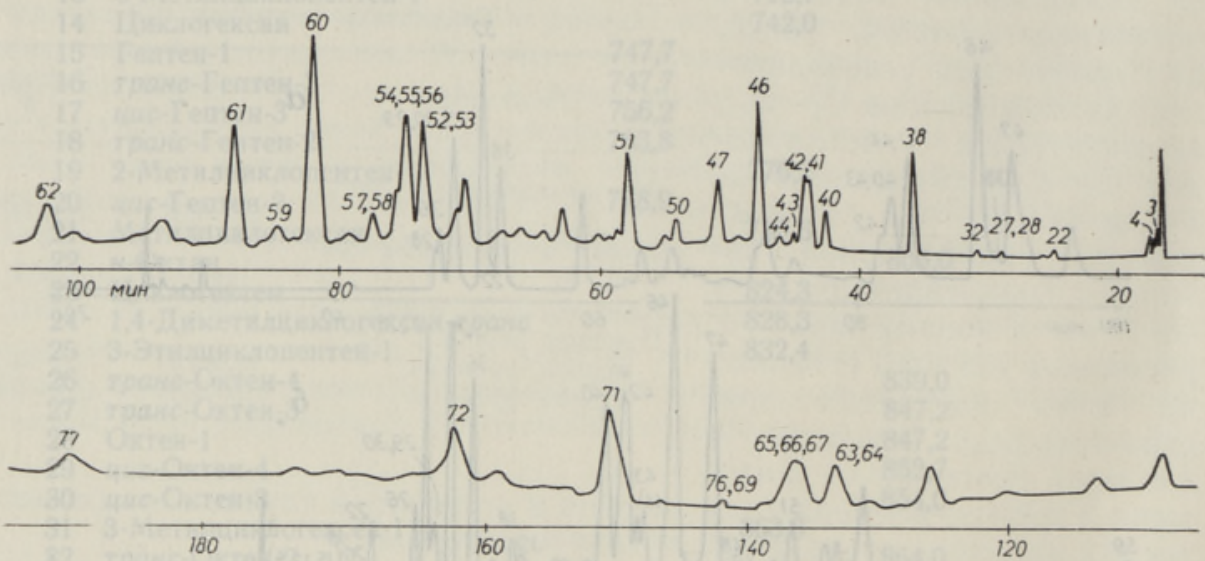

Рис. 3. Хроматограмма олефиновой фракщии дистиллята $R_{2}$, разделенной при помощи адсорбщионно-жидкостной хроматографин.

Капиллярная колонка с полиэтнленгликолем 4000 длиной 40 м: температура колонки $62^{\circ} \mathrm{C}$; входное давление $1,30 \kappa 2 / \mathrm{cM}^{2}$.

жании 1-олефинов объясняется их изомеризацией в процессе разделения дистиллятов методом адсорбционно-жидкостной хроматографии на силикагеле.

Подробнее вопрос изомеризации олефинов будет рассматриваться в работе [19. Для проверки соответствия состава фракций, полученных в тонком слое, составам фракций в начальных дистиллятах, сравнивались дистилляты $K_{1}$ и $R_{1}$. В табл. 5 приведены результаты этого сравнения, которые в целом совпадают.

Следовательно, можно сказать, что в олефиновой части дистиллятов $\left(K_{1}, R_{1}, K_{2}, R_{2}\right)$ коксования сланцевой смолы содержится н-олефинов от $\mathrm{C}_{7}$ до $\mathrm{C}_{11} ; 1$-олефины составляют около 60 и 2 -олефины $-20-30 \%$ от состава всех олефинов. При этом транс-2-изомеров в пробах было примерно в два раза больше, чем циис-2-изомеров.

Сравнение составов олефиновых дистиллятов, полученных при двух разных режимах коксования $\left(K_{1}, R_{1}\right)$, показало, что никакого качественного различия в этих пробах нет. В то же время в дистилляте $R_{1}$ обнаружено больше олефинов с высокими температурами кипения. 


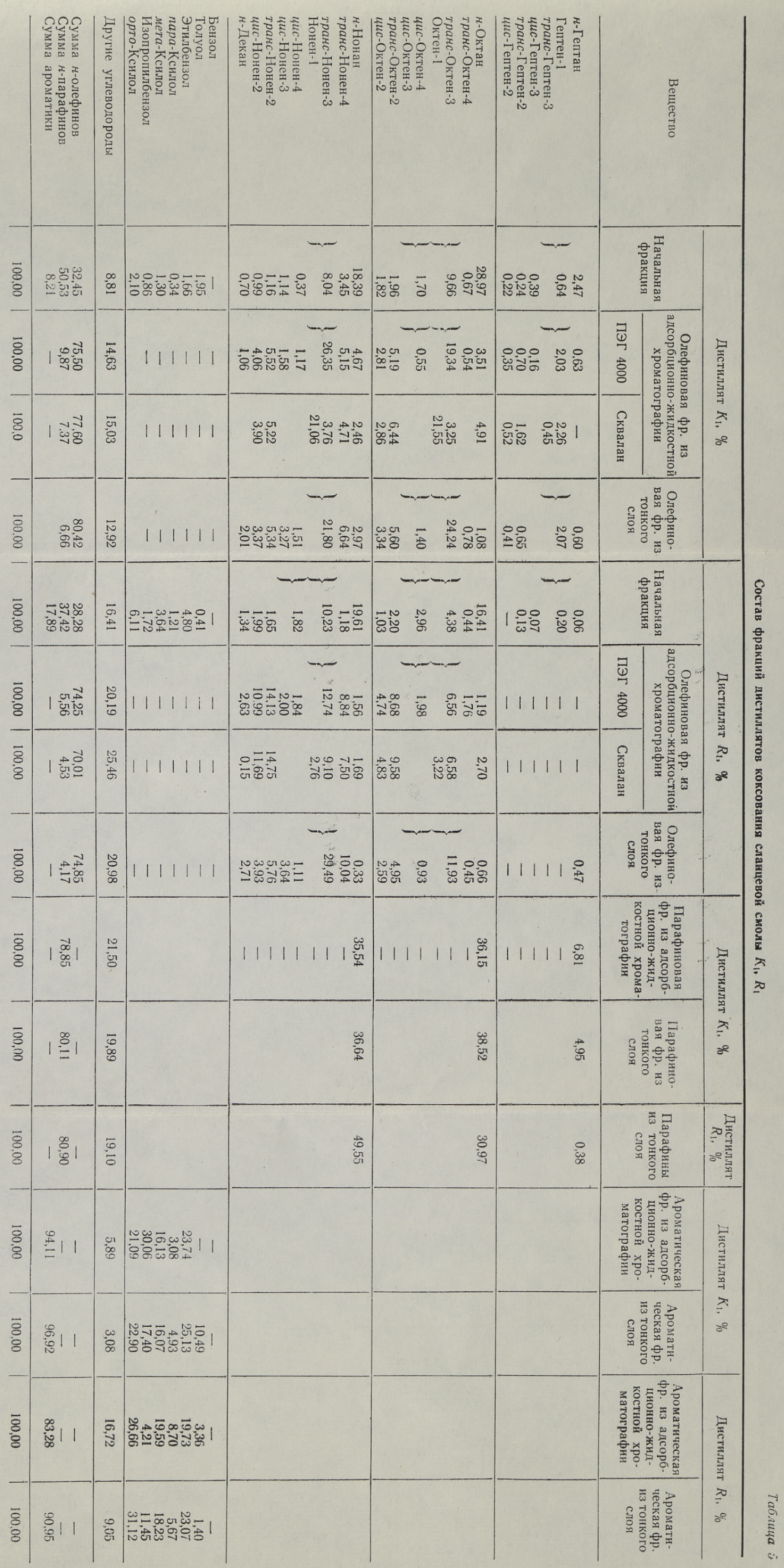




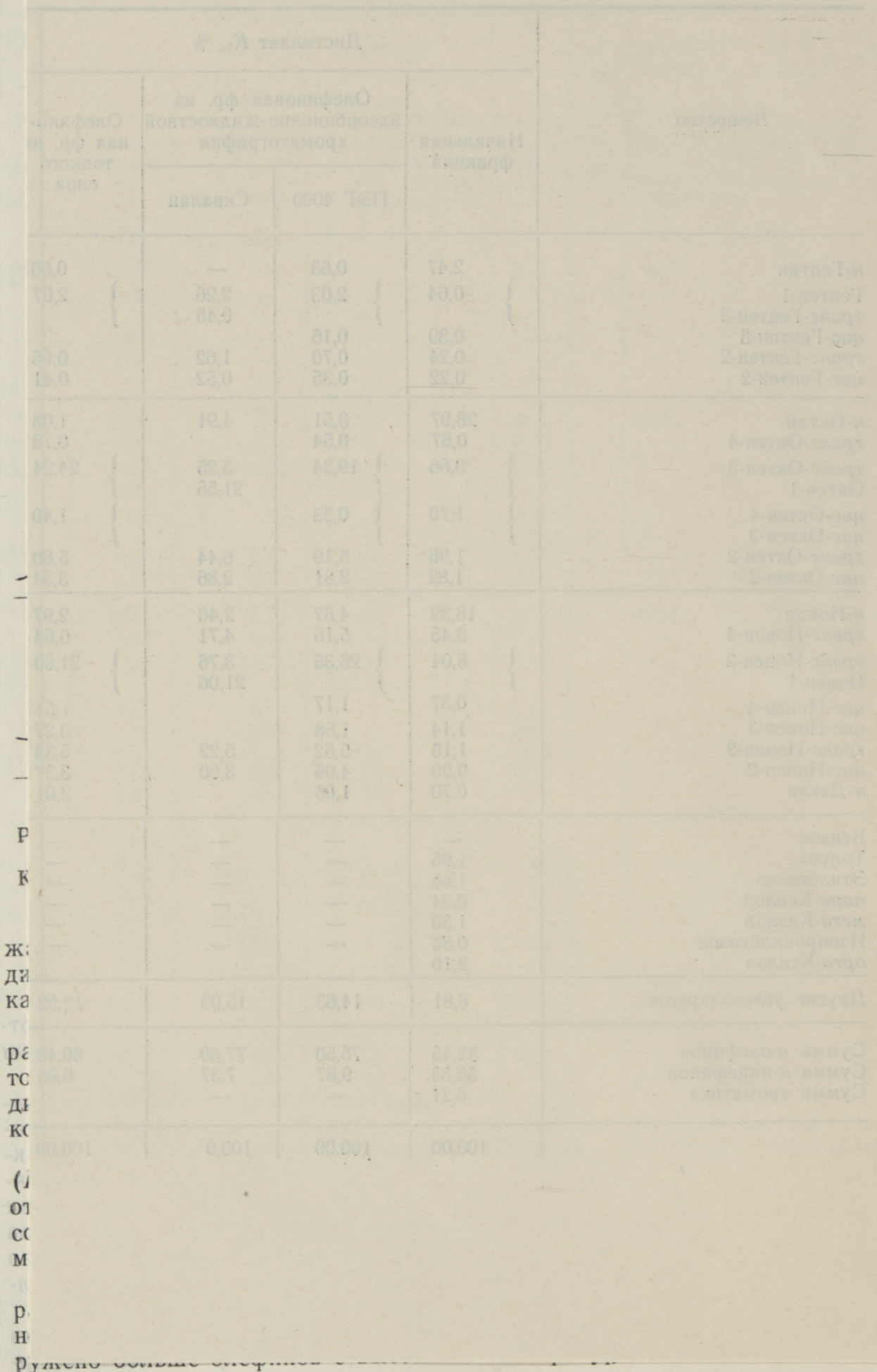




\section{Таблица 6}

Состав олефиновой части дистиллятов коксования $K_{2}$ и $R_{2}$

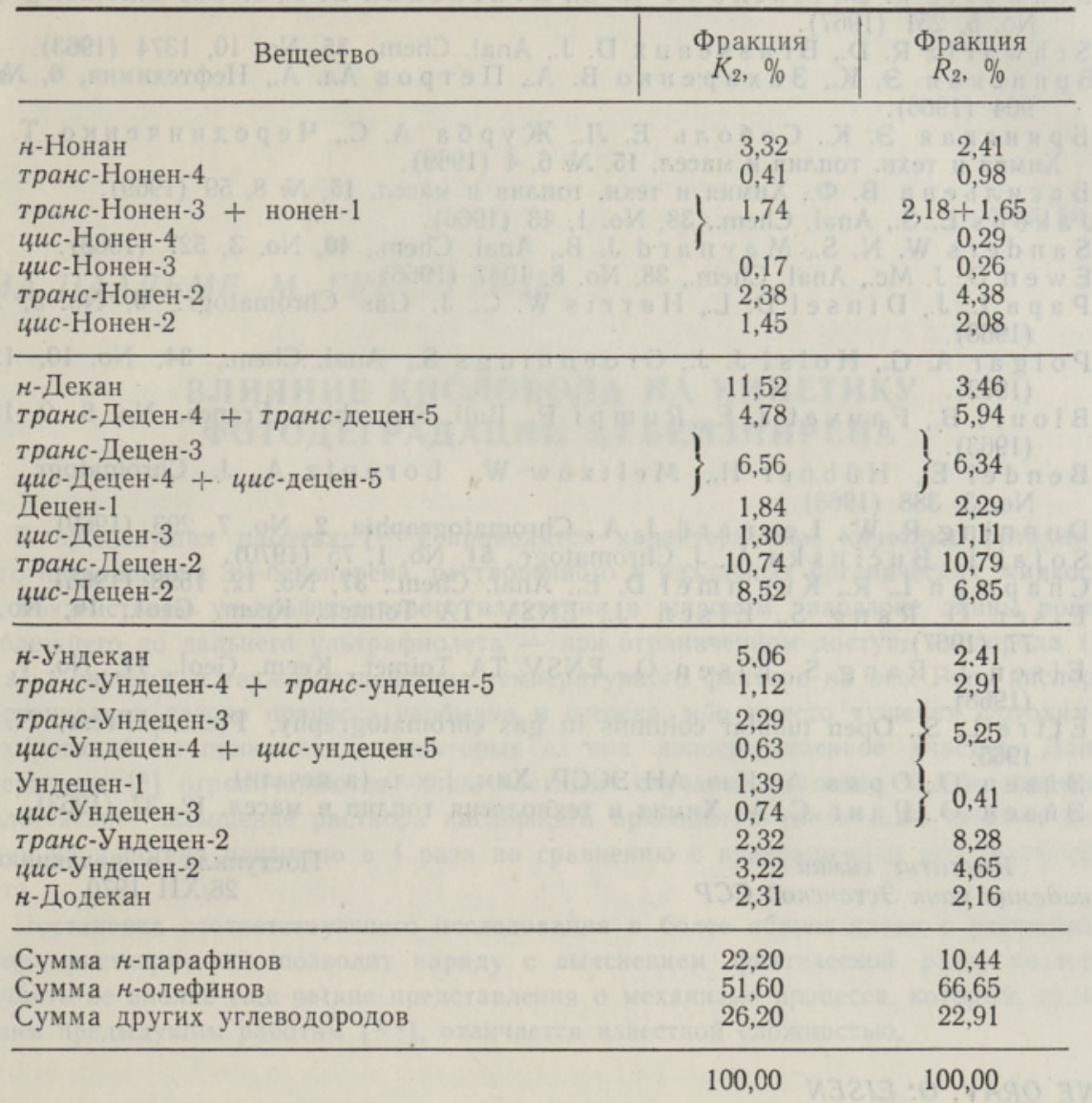

На хроматограммах олефиновых фракций дистиллятов $K_{1}$ и $R_{1}$ было идентифицировано 26 и 30 пиков соответственно из 30 и 40 возможных. $\mu$-Олефины составляли во фракциях $75-80, \mu$-парафины $4-6$ и другие углеводороды $12-20 \%$. Из последних были идентифицированы цикланы и циклены. Неидентифицированные пики принадлежат, очевидно, изопарафинам и изо-олефинам, которые не удалось установить из-за отсутствия эталонных веществ. На хроматограмме тяжелых олефиновых фракций (рис. 3) было идентифицировано 35 -парафинов и $н$-олефинов.

Определение состава начальной фракции дистиллята показало, что основную часть дистиллятов составляли $\boldsymbol{H}$-парафины: $\boldsymbol{H}$-парафины 50 , $\mu$-олефины $30 \%$. Сравнивая эти результаты с составом бензиновой фракции туннельных печей, выкипающей до $150^{\circ}$, видно, что в ней основными являются н-олефины: $н$-парафинов 20,09 и н-олефинов $35,49 \%$ [20]. Парафиновая часть дистиллятов $K_{1}$ и $R_{1}$ состояла в основном из $H$-нонана и н-октана.

В ароматической части обнаружены мета- и орто-ксилолы, а также этилбензол и изопропилбензол. 
I. Schwartz R. D., Mathews R. G., Brasse a ux D. J., J. Gas Chromatogr., 5, No. 5, 251 (1967).

2. Schwartz R. D., B r a s se a ux D. J., Anal. Chem., 35, No. 10, 1374 (1963).

3. Брянская Э. К., 3 ах а ренко В. А., Петров Ал. А., Нефтехимия, 6, № 6, 904 (1966).

4. Брянская Э. К., Соболь Е. Л., Журба А. С., Чередниченко Т. И., Химия и техн. топлив и масел, 15, № 6, 4 (1969).

5. В а с ил ве в а В. Ф., Химия и техн. топлив и масел, 15, № 8, 59 (1969).

6. J a k o b s E. S., Anal. Chem., 38, No. 1, 43 (1966).

7. S a nders W. N. S., Mayn a rd J. B., Anal. Chem., 40, No. 3, 527 (1968).

8. E w e n D. J. Mc., Anal. Chem., 38, No. 8, 1047 (1966).

9. P a p a L. J., D insel D. L., Harris W. C., J. Gas Chromatogr., 6, No. 5, 270 (1968).

10. Polgar A. G., Holst J. J., Groennings S., Anal. Chem., 34, No. 10, 1226 (1962).

I1. B louri B., Fauvet J. E., Rumpf P., Bull. Soc. chim. France, No. 8-9, 1855 (1963).

12. Bendel E., Hübner H., Meltzow W., Lorentz A., J. Chromatogr., 38, No. 3,388 (1968).

13. Dunn ing R. W., Leon a rd J. A., Chromatographia, 2, No. 7, 293 (1969).

14. S o j a k L., B uč i n sk a A., J. Chromatogr., 51, No. 1, 75 (1970).

15. Ch a p m a n L. R., Ku e m mel D. E., Anal. Chem., 37, No. 12, 1598 (1965)

16. Eisen O., Rang S., Eisen J., ENSV TA Toimet., Keem. Geol., 16, No. 1, 77 (1967).

17. E is en J., Rang S., E is en O., ENSV TA Toimet., Keem. Geol., 17, No. 1, 84 (1968).

18. Ettre L. S., Open tubular columns in gas chromatography, Plenum Press, N. Y., 1965.

19. Эй зе н О., Ор а в А., Изв. АН ЭССР, Хим. Геол. (в печати).

20. Эй зен О., Р ан г С. А., Химия и технология топлив и масел, 12, 37 (1963).

Институт химии

Академии наук Эстонской ССР

Поступила в редакцню $28 /$ XII 1970

\section{ANNE ORAV, O: EISEN}

\section{NORMAALSETE OLEFIINIDE MÄARAMINE POLLEVKIVIŌLI KOKSISTAMISE DESTILLAATIDES KAPILLAAR-GAASIKROMATOGRAAFIA ABIL}

Määrati $n$-olefiinide sisaldus põlevkiviōli destillaatides, mis olid saadud kahte erinevat koksistamisrežiimi kasutades.

Kasutati $80 \mathrm{~m}$ pikkust polüetüleenglükooliga 4000 kaetud kapillaarkolonni.

Leiti, et olefiinide fraktsiooni pôhikomponendi moodustavad 1-olefiinid $(60 \%)$. $20-30 \%$ olefiinidest olid trans-2 ja cis-2 isomeerid, kusjuures trans-2 isomeeri oli destilTaatides poole rohkem kui cis-2 isomeeri.

$n$-parafiinid moodustasid destillaatide koostisest $50, n$-olefiinid $30 \%$.

\section{ANNE ORAV, O. EISEN}

\section{THE DETERMINATION OF NORMAL OLEFINS IN THE DISTILLATES OF COKING OF SHALE OIL BY CAPILLARY GAS CHROMATOGRAPHY}

The composition of normal olefins in the distillates of coking of shale oils has been determinated, using $80 \mathrm{~m}$ capillary column coated with polyethylene glycol 4000 .

$50 n$-paraffins and $n$-olefins have been identified by means of Kovats' indexes.

The main components in the olefinic fractions were 1-olefins $(60 \%)$, trans-2-olefins and cis-2-olefins $(20-30 \%)$.

In the distillates, $n$-paraffins formed 50 per cent and $n$-olefins -30 per cent. 